Acknowledgements: Medical writing services provided by Alan Saltzman of Fishawack Facilitate Ltd, part of Fishawack Health, and funded by AbbVie. The design, study conduct, and financial support for the study were provided by AbbVie. AbbVie participated in the interpretation of data, review, and approval of the abstract. No honoraria or payments were made for authorship.

Disclosure of Interests: Atul Deodhar Speakers bureau: Novartis, Pfizer, Consultant of: Novartis, Pfizer, AbbVie, Eli Lilly, UCB Pharma, GlaxoSmithKline, Galapagos, Janssen, Boehringer Ingelheim, Celgene, Amgen, Grant/ research support from: Novartis, Pfizer, AbbVie, Eli Lilly, UCB Pharma, GlaxoSmithKline, Denise Kruzikas Shareholder of: AbbVie, Employee of: AbbVie, Lili Zhou Employee of: AbbVie, Ana Biljan Shareholder of: AbbVie, Employee of: AbbVie, Christopher Saffore Shareholder of: AbbVie, Employee of: AbbVie

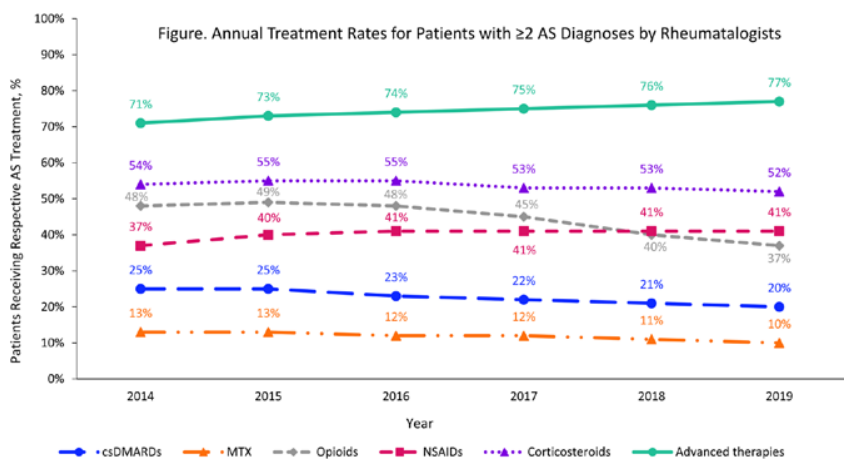

Figure 1.

DOI: 10.1136/annrheumdis-2021-eular.202

\section{POS0944 \\ AGE AT ONSET IN AXIAL SPONDYLOARTHRITIS AROUND THE WORLD: DATA FROM THE INTERNATIONAL ASAS-PERSPA STUDY}

A. Boel ${ }^{1}$, C. López-Medina ${ }^{2}$, D. Van der Heijde ${ }^{1}$, F. A. Van Gaalen ${ }^{1}{ }^{1}{ }^{1}$ Leiden University Medical Centre, Rheumatology, Leiden, Netherlands; ${ }^{2}$ Cochin Hospital, Assistance Publique Hôpitaux de Paris, Rheumatology, Paris, France

Background: Axial spondyloarthritis (axSpA) typically begins in young adulthood and age at onset is therefore very useful in identifying chronic back patients at an increased risk of axSpA. Age at onset below the age of 45 has been incorporated into the 2009 ASAS classification criteria for axSpA as a mandatory feature. However, inclusion of age at onset before the age of 45 was based on a small number of Western European studies and it is therefore unknown if this age at onset applies to patients in other parts of the world.

Objectives: The aim of this study was to assess age at onset of axSpA as well as its relationship with HLA-B27 throughout the world, using data from the Assessment in SpondyloArthritis international Society (ASAS) peripheral involvement in Spondyloarthritis (ASAS-perSpA) study.

Methods: Analyses were restricted to patients with an axSpA diagnosis who had information available on age at onset of axial complaints. Cumulative probability plots were used to graphically display the cumulative distribution of age at onset of axial symptoms. Linear regression models were built to assess

Table 1. Percentage of axSpA patients with an age at onset of axial symptoms $<40,<45$ and $<50$ years stratified by geographical region and HLA-B27 status.

\begin{tabular}{|c|c|c|c|c|c|c|c|c|}
\hline & \multicolumn{4}{|c|}{ HLA-B27 positive } & \multicolumn{4}{|c|}{ HLA-B27 negative } \\
\hline & $N$ & $\begin{array}{c}\text { Age at } \\
\text { onset }<40\end{array}$ & $\begin{array}{c}\text { Age at } \\
\text { onset }<45\end{array}$ & $\begin{array}{c}\text { Age at } \\
\text { onset }<50\end{array}$ & $N$ & $\begin{array}{c}\text { Age at } \\
\text { onset }<40\end{array}$ & $\begin{array}{c}\text { Age at } \\
\text { onset }<45\end{array}$ & $\begin{array}{c}\text { Age at } \\
\text { onset }<50\end{array}$ \\
\hline Asia & 469 & $91 \%$ & $94 \%$ & $97 \%$ & 56 & $79 \%$ & $88 \%$ & $95 \%$ \\
\hline $\begin{array}{l}\text { Europe \& } \\
\text { North } \\
\text { America }\end{array}$ & 678 & $88 \%$ & $94 \%$ & $98 \%$ & 184 & $74 \%$ & $85 \%$ & $93 \%$ \\
\hline Latin America & 157 & $81 \%$ & $94 \%$ & $96 \%$ & 38 & $45 \%$ & $76 \%$ & $84 \%$ \\
\hline $\begin{array}{l}\text { Middle East } \\
\text { \& North } \\
\text { Africa }\end{array}$ & 320 & $88 \%$ & $94 \%$ & $98 \%$ & 161 & $84 \%$ & $88 \%$ & $94 \%$ \\
\hline Total & 1624 & $88 \%$ & $94 \%$ & $97 \%$ & 439 & $76 \%$ & $86 \%$ & $93 \%$ \\
\hline
\end{tabular}

the effect of HLA-B27 status on age at onset of axial symptoms. As axSpA is a multifactorial, multigenetic disease, geographical region was investigated as an effect modifier.

Results: The majority (92\%) of patients with axSpA had an age at onset of axial symptoms below 45 years, with only small variation across the various geographical regions (table 1). Cumulative distribution plots showed age at onset of axial symptoms was consistently lower in HLA-B27 positive patients (in blue) than in HLA-B27 negative patients (in red) across all geographical regions (Figure 1 below). Linear regression models showed a significant effect of HLA-B27 status on the age at onset of axial symptoms in the total study population $(p<0.001)$, and Latin American $(p<0.001)$, European \& North American $(p<0.001)$, Asian $(p=0.006)$ and Middle Eastern \& North African $(p=0.005)$ populations. There was no effect modification of geographical region $(p=0.50)$ on the association between HLA-B27 status and age at onset of axial symptoms.

Conclusion: Irrespective of geographical region, the majority of axSpA patients had an age at onset of axial disease before the age of 45 . In all populations, HLA-B27 was associated with earlier disease onset. These results provide crucial data for diagnosis, classification, and policies aimed at improving recognition of $\operatorname{axSpA}$.

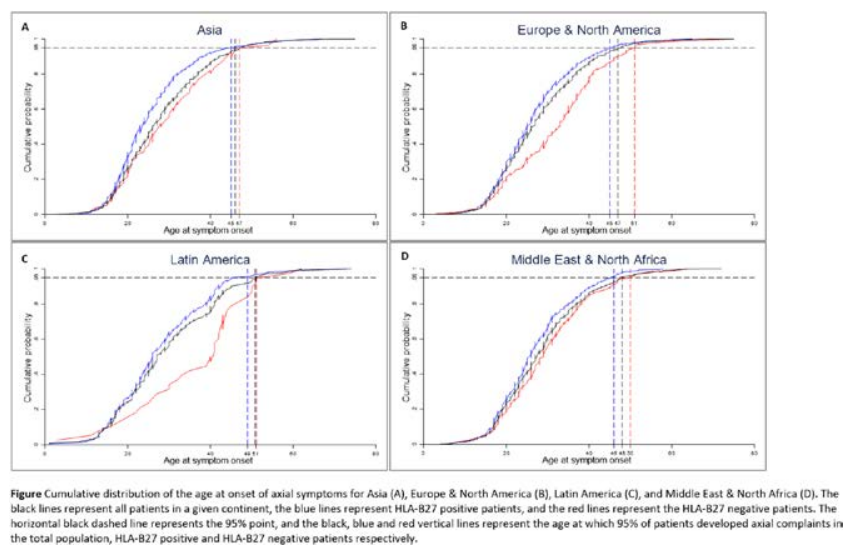

Figure 1.

Acknowledgements: We would like to thank all ASAS-perSpA investigators and members of the scientific committee

Disclosure of Interests: None declared

DOI: 10.1136/annrheumdis-2021-eular.218

\section{POS0945 NON-RADIOGRAPHIC AXIAL SPONDYLOARTHRITIS IN THE AFRO-CARIBBEAN POPULATION, CLINICAL ASPECTS AND PARTICULARITIES}

F. Louis-Sidney ${ }^{1}$, D. Morillon ${ }^{2}$, M. Blettery ${ }^{1}$, L. Brunier ${ }^{1}$, P. Numeric ${ }^{3}$, M. De Bandt ${ }^{2}{ }^{1}$ Hopital La Maynard Martinique, Rheumatology, Fort-de-France, Martinique; ${ }^{2}$ Hopital La Maynard Martinique, Radiology, Fort-de-France, Martinique; ${ }^{3}$ Hopital La Maynard Martinique, Rheumatology, Fort-de-France, Martinique

Background: Spondyloarthritis is a polymorphic disease and the absence of diagnostic marker has led to propose diagnostic criteria for recognition All the criteria, established in Caucasian populations, place at the center of the approach sacroiliac imaging and genetic terrain (HLA B27). For this reason, these criteria are not appropriate in populations lacking HLA B27. SPA is known to be rare in African populations and this rarity correlates with that of HLA B27.Prevalence of B27 in French West Indies is $2 \%$ (identical to the African populations)

Objectives: We report clinical manifestations of $\mathrm{SpA}$ seen at the Fort de France University Hospital, with an emphasis on the so-called "non-radiographic SpA" (NRSPA).

Methods: Adult patients with spondyloarthritis seen over a period of three consecutive months, were invited to participate in a survey and filled-in a self-administered questionnaire. The consulting rheumatologist specified the rheumatologic and extra-articular involvement, BASDAI score, HLAB27 data, markers of inflammation and imaging. 
Results: There were 93 patients, 47 with radiographic sacroilitis (RSPA) and 46 patients without but all - these 46 - had magnetic sacroilitis. This population is Afro-Caribbean for $98 \%$. Mean age at onset of clinical signs is $38.5 \pm 15.0$ years and median age is 37.0 (13-77). An evocative family history is noted in $37 \%$. All these 93 patients suffer from rachialgia.

But the axial complaint is often secondary to the peripheral involvement. 3 patients have a mechanical spinal complaint. All the others have intermittent inflammatory complaint evolving by flares affecting all the spinal stages. 15/93 patients have isolated axial complain without peripheral disease. Enthesopathies are seen in $70 \%$.

Peripheral inflammatory joint complain is observed in 78 patients $(84 \%)$, it is a bilateral and symmetrical chronic polyarticular pattern affecting (70/78) the small joints of the hands, forefeet and wrists. Ankle bi-arthritis is almost systematic and is observed in 71/78 patients; 8 patients with RSPA had no polyarthritis but oligo (6) or monoarthritis (2). Peripheral inflammatory joint is more frequent in NRSPA than in RSPA ( $98 \%$ vs $70 \%)$. Ultrasound individualises grade II synovitis (78/78), rarely with a Doppler effect (5/78). On average, more painful and swollen joints are observed in NRSPA than in RSPA. Extra articular and immunological aspects and activity scores are in table 1.

Good sensitivity of peripheral arthritis to NSAIDs and MTX is noted in 94 and $91 \%$.

Conclusion: NRSpA are not uncommon in the Afro-Caribbean population, but are distinct from Caucasian SpA by several points: female predominance, rarity of B27 and syndesmophytes, frequency of polyalgic pattern, frequency of peripheral arthritis, rarity of extra-articular manifestations, more frequent but less marked inflammation, good response of arthritis to NSAIDs and MTX. Appropriate classification criteria for Afro-descendant populations is an urgent unmet need.

REFERENCES:

[1] (López-Medina C, et al. RMD Open 2019;5:e001108).

Table 1. Extra articular manifestations, activity scores and immunological aspects of the patients.

\begin{tabular}{lcc}
\hline Item & $\begin{array}{c}\text { Results }(\%) \\
\text { NRSPA } n=46\end{array}$ & $\begin{array}{c}\text { Results }(\%) \\
\text { RSPA } n=47\end{array}$ \\
\hline Dactylitis & $11(23 \%)$ & $13(27 \%)$ \\
Uvéitis & $5(11 \%)(\mathrm{p} \mathrm{0.02)}$ & $15(32 \%)$ \\
Psoriasis & $1(2 \%)$ & $1(2 \%)$ \\
IBD & $4(9 \%)(\mathrm{p} 0.02)$ & $10(21 \%)$ \\
Balanitis & 0 & 0 \\
Non gonococcal urethritis & 0 & 0 \\
Non gonococcal cervicitis & 0 & 0 \\
High CRP (at least 2 measure) & $21(45 \%)(\mathrm{p} 0.03)$ & $30(63 \%)$ \\
Mean CRP mg/l & $6 \pm 4$ & $17 \pm 7$ \\
BASDAl & $4.1 \pm 0.2$ & $4 \pm 0.2$ \\
EVA pain & $4.5 \pm 0.4$ & $4,5 \pm 0.2$ \\
HAQ & $0.6 \pm 0.3$ & $0,5 \pm 0.2$ \\
EVA Global & $4.9 \pm 0.8$ & $4,8+0.8$ \\
EVA Spine & $5 \pm 0.5$ & $4,1+0.9$ \\
FIRST score $>5$ & $5 / 46$ patients $(10.9 \%)$ & $6 / 47$ patients $(12.5 \%)$ \\
HLA B27 presence & $4 / 46(8.7 \%)(\mathrm{p} 0.01)$ & $14 / 47(29.8 \%)$ \\
Sexe & male $10(21.3 \%)(\mathrm{p} 0.001)$ & male $19(51.3 \%)$ \\
ACPA & 0 & 0 \\
Latex Waaler-Rose & $1($ low titer, $>65$ years) & 1 (low titer, $>65$ years) \\
ANA & 2 (low titer, $\left.<1 / 320^{\circ}\right)$ & 3 (low titer, $\left.<1 / 320^{\circ}\right)$ \\
\hline
\end{tabular}

Disclosure of Interests: None declared

DOI: 10.1136/annrheumdis-2021-eular.260

\section{POS0946 DISTRIBUTION OF COMORBIDITIES IN SPONDYLOARTHRITIS WITH REGARD TO THE PHENOTYPE AND THE PRESENCE OF PSORIASIS: DATA FROM THE ASAS-COMOSPA STUDY}

M. Á. Puche Larrubia ${ }^{1}$, M. L. Ladehesa Pineda ${ }^{1}$, F. U. Pilar ${ }^{2}$, A. Moltó ${ }^{3}$, C. López-Medina ${ }^{1,3}$, E. Collantes-Estevez ${ }^{1}{ }^{1}$ Reina Sofía University Hospital, Rheumatology, Córdoba, Spain; ${ }^{2}$ University of Cordoba, Rheumatology, Córdoba, Spain; ${ }^{3}$ Cochin Hospital, Rheumatology, Paris, France

Background: Comorbidities have been reported to be more prevalent in patients with Spondyloarthritis (SpA) compared to the general population. Previous studies have suggested that patients with peripheral phenotypes exhibit a higher prevalence of traditional cardiovascular risk (CV) factors compared to those with a predominantly axial phenotype. However, the role of psoriasis in such differences has not been deeply studied.
Objectives: To compare the prevalence of comorbidities (CV, malignancies and osteoporosis (vertebral or peripheral fracture, or low bone mineral density)) between patients with axial and peripheral phenotypes and to evaluate the role of psoriasis in such comorbidities in the whole spectrum of SpA (including psoriatic arthritis).

Methods: Patients from the cross-sectional ASAS-COMOSPA study were classified as having either axial (presence of sacroiliitis on $x$-ray or MRI) or peripheral phenotype (absence of sacroiliitis AND presence of arthritis enthesitis or dactylitis). Patients with each phenotype were divided into two groups depending on the presence or history of psoriasis. Pair-wise comparisons among the four groups (axial and peripheral with psoriasis/withou psoriasis phenotypes) were conducted through univariate logistic regressions and generalized linear mixed models using disease duration and country as fixed and random effects, respectively. Multivariate analysis using were used to evaluate whether psoriasis and the phenotype are independently associated with each comorbidity.

Results: A total of 3291 patients were included in this analysis (mean age 43.6 years, $65 \%$ males). The peripheral phenotype with psoriasis showed the highest prevalence of hypertension (44.9\%), dyslipidaemia (34\%) and diabetes $(8.8 \%)$, while axial phenotype without psoriasis exhibited the lowest prevalence of dyslipidaemia (14.2\%), diabetes (4.1\%) and stroke (0.9\%) (Table 1$)$ Among patients with psoriasis, the axial phenotype showed a significantly [OR, 95\% Cl] lower prevalence of hypertension [OR 0.5, 0.4-0.8] and lower Framingham score [OR $0.97,0.95-0.99$ ] compared to peripheral patients even after adjusting for disease duration and country. Among patients with axial phenotype, patients with psoriasis showed higher prevalence of hypertension [OR 1.8, 1.4-2.2], dyslipidaemia [OR 2.0, 1.7-2.5], diabetes [OR 2.1, 1.4-3.0] and Framingham score [OR 1.0, 1.0-1.1] than non-psoriatic patients. Multivariate analysis confirmed that hypertension, dyslipidaemia and the Framingham score are independently associated with both the psoriasis and the periphera phenotype.

Prostatic cancer and colon cancer were independently associated with the pres ence of psoriasis but not with the phenotype. No differences were found across groups concerning osteoporosis.

Conclusion: Both a peripheral phenotype and the presence of psoriasis were independently associated with an increased CV risk. Psoriasis seems to be associated with a higher prevalence of some malignant diseases, while osteoporosis do not seem to be associated with either phenotype or the presence of cutaneous involvement.

Table 1. Description of comorbidities across the four groups.

\begin{tabular}{lccccc}
\hline & $\begin{array}{c}\text { Psoriatic } \\
\text { axial } \\
\mathbf{N}=\mathbf{4 6 0} \\
\mathrm{n}(\%)\end{array}$ & $\begin{array}{c}\text { Non-psoriatic } \\
\text { axial } \\
\mathbf{N}=\mathbf{2 5 4 1} \\
\mathrm{n}(\%)\end{array}$ & $\begin{array}{c}\text { Psoriatic } \\
\text { peripheral } \\
\mathbf{N}=\mathbf{1 4 7} \\
\mathrm{n}(\%)\end{array}$ & $\begin{array}{c}\text { Non-psoriatic p-value* } \\
\text { peripheral } \\
\mathbf{N}=\mathbf{1 3 6} \\
\mathrm{n}(\%)\end{array}$ & \\
& $27.4(5.5)$ & $25.5(5.5)$ & $27.3(5.7)$ & $26.6(5.3)$ & $<0.001$ \\
\hline BMI, mean (SD) & $135(29.5)$ & $487(19.2)$ & $66(44.9)$ & $25(18.4)$ & $<0.001$ \\
Hypertension & $113(24.8)$ & $359(14.2)$ & $50(34)$ & $23(17)$ & $<0.001$ \\
Dyslipidemia & $37(8.1)$ & $104(4.1)$ & $13(8.8)$ & $7(5.2)$ & $<0.001$ \\
Diabetes & $16(3.5)$ & $51(2)$ & $5(3.4)$ & $2(1.5)$ & 0.162 \\
Ischemic heart disease & $11(2.4)$ & $22(0.9)$ & $3(2)$ & $2(1.5)$ & $\mathbf{0 . 0 2 8}$ \\
Stroke & $9.6(8.7)$ & $6.6(7.5)$ & $11.8(8.8)$ & $5.8(6)$ & $<0.001$ \\
Framingham score, & & & & & \\
$\quad$ mean (SD) & $5(1.8)$ & $5(0.3)$ & $0(0)$ & $0(0)$ & $\mathbf{0 . 0 0 6}$ \\
Prostatic cancer & $(1.7)$ & $3(0.4)$ & $1(1.4)$ & $0(0)$ & 0.181 \\
Breast cancer & $4(0.9)$ & $4(0.2)$ & $1(0.7)$ & $1(0.7)$ & $\mathbf{0 . 0 4 6}$ \\
Colon cancer & $6(1.3)$ & $9(0.4)$ & $1(0.7)$ & $4(3)$ & $<0.001$ \\
Basal cell carcinoma & $0(0)$ & $4(0.2)$ & $3(2)$ & $0(0)$ & $<0.001$ \\
Lymphoma & & & & & \\
\hline
\end{tabular}

*ANOVA or chi-square for continuous and qualitative variables, respectively.

Acknowledgements: This study was conducted under the umbrella of the International Society for Spondyloarthritis Assessment (ASAS).

Disclosure of Interests: None declared

DOI: 10.1136/annrheumdis-2021-eular.306

\section{POS0947 PSORIATIC ARTHRITIS WITH HYPERURICEMIA: MORE PERIPHERAL, DESTRUCTIVE AND CHALLENGINGTO TREAT}

L. Widawski ${ }^{1}$, T. Fabacher ${ }^{2}$, J. E. Gottenberg ${ }^{3}$, L. Spielmann ${ }^{1}$, P. M. Duret ${ }^{1}$, J. Sibilia ${ }^{3}$, L. Messer ${ }^{1}$, R. Felten ${ }^{3} .{ }^{1}$ Hôpitaux Civils de Colmar, Rheumatology, Colmar, France; ${ }^{2}$ Nouvel Hôpital Civil - Hôpitaux Universitaires de Strasbourg, Epidemiology and Public Health, Strasbourg, 